\title{
New frontiers in chronic lymphocytic leukemia on the way to curing the disease
}

\author{
Philipp Staber
}

Accepted: 7 January 2022

(c) The Author(s), under exclusive licence to Springer-Verlag GmbH Austria, part of Springer Nature 2022

Chronic lymphocytic leukemia (CLL) is the most common leukemia in the western world and is considered to be incurable. In the last 10 years, novel therapeutics, like B cell receptor blockers and the bcl-2 inhibitor venetoclax have transformed the prognosis for CLL patients [1]. In this issue of the Magazine of European Medical Oncology (MEMO), we discuss the perspectives of novel strategies to actually cure CLL patients.

Daniel Heintel reviews the current treatment options for patients with CLL with respect to potential optimal treatment combinations [2]. Katharina Prochazka analyzes the effects and consequences of venetoclax-based regimens to induce deep remissions [3] and Jan-Paul Bohn presents the perspectives of a potentially bright future with new targets and drugs for CLL.

Conflict of interest P. Staber has received honoraria for lectures, consultation or advisory board participation from the following for-profit companies: Takeda, Bristol-Myers Squibb, Novartis, BeiGene, Incyte, GlaxoSmithKline, Janssen, Roche, MedMedia, Astra Zeneca, AbbVie, Amgen, Medahead, Sanofi, Merck Sharp \& Dome.

Univ.-Prof. Dr. P. Staber $(\bowtie)$

Clinical Division of Oncology, Department

of Medicine I, Medical University of Vienna,

Währinger Gürtel 18-20, 1090 Vienna, Austria

philipp.staber@meduniwien.ac.at

\section{References}

\section{Cited Literature}

1. Hallek M, Cheson BD, Catovsky D, Caligaris-Cappio F, Dighiero G, Döhner H, et al. iwCLL guidelines for diagnosis, indications for treatment, response assessment, and supportive management of CLL. Blood. 2018;131:2745-60.

2. Heintel D. BTKi, venetoclax, obinutuzumab: what is the ideal combination?. memo. 2021. https://doi.org/10.1007/ s12254-021-00776-4.

3. Prochazka KT, Uhl B. Bcl2 inhibitor venetoclax +/- AntiCD20: what do deep remissions mean?. memo. 2021. https://doi.org/10.1007/s12254-021-00778-2.

\section{Further Reading}

4. Bohn J-P. New actionable targets and investigational drugs in chronic lymphocytic leukemia. memo. 2021. https:// doi.org/10.1007/s12254-021-00755-9.

Publisher's Note Springer Nature remains neutral with regard to jurisdictional claims in published maps and institutional affiliations.

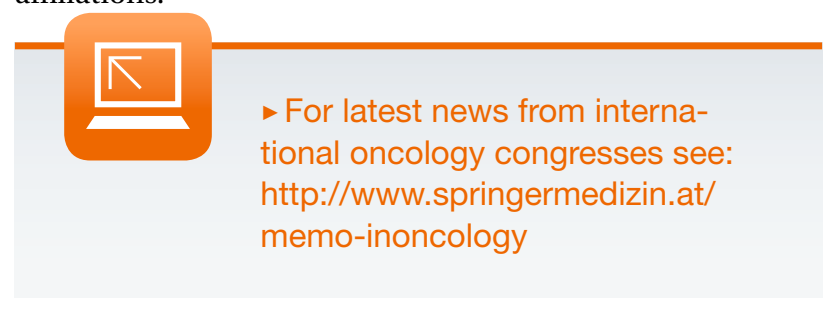

